\title{
Characterization of Allele Diversity in a Microsatellite Locus: A Registry for Solenopsis invicta
}

\author{
Rodrigo Fernando de Souza ${ }^{1}$, Fernando Kamimura Cocchi², Cíntia Martins ${ }^{3}$, \\ Maria Santina de Castro Morini' ${ }^{1}$, Odair Correa Bueno ${ }^{2}$ \\ ${ }^{1}$ Núcleo de Ciências Ambientais, Universidade de Mogi das Cruzes, Mogi das Cruzes, Brasil \\ ${ }^{2}$ Centro de Estudos de Insetos Sociais, Instituto de Biociências, Campus Rio Claro, Universidade Estadual \\ Paulista Julio de Mesquita Filho, Rio Claro, Brasil \\ ${ }^{3}$ Campus Ministro Reis Veloso, Universidade Federal do Piauí, Parnaíba, Brasil \\ Email: *souza_bio@yahoo.com.br
}

Received 5 December 2015; accepted 18 January 2016; published 21 January 2016

Copyright (C) 2016 by authors and Scientific Research Publishing Inc.

This work is licensed under the Creative Commons Attribution International License (CC BY). http://creativecommons.org/licenses/by/4.0/

(c) (i) Open Access

\section{Abstract}

The genus Solenopsis includes more than 100 species in the New World. When introduced, some species cause serious harm to the native wildlife and agriculture. Two forms of social organization are known in the genus, namely, monogyne and polygyne. Here, we present the genetic profile of a Solenopsis invicta Buren 1972 colony recorded in the central region of the city of São Paulo, São Paulo state, Brazil $\left(23^{\circ} 33^{\prime} 37.18 " \mathrm{~S} ; 4^{\circ} 42^{\prime} 48.66^{\prime \prime} \mathrm{W}\right)$ to describe allele diversity. Eight microsatellite loci were used for the analysis of 30 worker ants. The results show the presence of seven alleles genotyped at the same microsatellite locus. Because this is an unusual finding, all of the alleles were sequenced, and surprisingly, an eighth allele was identified. These data suggest that the intracolonial genetic profile of fire ants must be investigated more frequently because there may be unexpected, albeit unknown, genetic patterns for $S$. invicta that can help inform better control and management programs.

\section{Keywords}

Fire Ants, Intracolonial, Microsatellites, Alleles

\section{Introduction}

The genus Solenopsis Westwood 1840 is known in Brazil as formiga-lava-pé, or simply as lava-pés or formi-

${ }^{*}$ Corresponding author.

How to cite this paper: de Souza, R.F., Cocchi, F.K., Martins, C., de Castro Morini, M.S. and Bueno, O.C. (2016) Characterization of Allele Diversity in a Microsatellite Locus: A Registry for Solenopsis invicta. Advances in Entomology, 4, 32-36. 
ga-de-fogo (fire ant). This genus includes approximately 216 species, of which 108 occur in the New World [1] [2]. The species are omnivorous and opportunistic, feeding on insects and other alive or dead small invertebrates, as well as on plant matter [3].

Native from South America, Solenopsis invicta Buren (1972) was accidentally introduced in many countries and has become a great public concern, causing serious damage to crops, livestock, native biodiversity, and human health [4]-[7]. The potential global range expansion of S. invicta has been correlated with temperature and precipitation, and abrupt variations of these factors may limit the success of the expansion [4].

There are two known forms of social organization in S. invicta: monogyne and polygyne. Monogyne social form is headed by single egg-laying queens, whereas polygyne social form contains multiple egg-laying queens [8]. Polygyne colonies have a greater impact than the monogyne colonies because they have high population densities and consume a large amount of organic matter [9].

Analyzing the genetic profile of native or introduced populations may assist in the understanding and planning of more effective control strategies. Introduced populations of potentially invasive ants show marked differences in their biology compared with native populations, such as changes in behavior, social organization, reproductive biology, and genetic profile [10].

The intracolony genetic profile is seldom explored because genetic analyses of microsatellite markers in the genus Solenopsis using few individuals (between 1 and 10) per colony [11]-[13] may hide internal diversity and influence conclusions regarding the species' social and reproductive dynamics. In many cases, these studies require individual analyses of worker ants from the same colony [14].

The objective of this study was to determine the intracolony allele diversity of $S$. invicta by analyzing eight microsatellite loci. The bioecology of this species is well studied, but genetic information is still scarce in the areas of natural occurrence.

\section{Methods}

The S. invicta colony was collected in the central region of the city of São Paulo, São Paulo state, Brazil (23 33'37.18"S; 46 $\left.42^{\prime} 48.66^{\prime \prime} \mathrm{W}\right)$, and the worker ants were subjected to DNA barcoding [15]-[17]. Social condition was investigated using two sets of primers described by Valles and Porter [18]-26BS (5'-

CTCGCCGATTCTAACGAAGGA-3'), 16BAS (5'-ATGTATACTTTAAAGCATTCCTAATATTTTGTC-3'), 24bS (5'-TGGAGCTGATTATGATGAAGAGAAAATA-3') and 25bAS (5'-

GCTGTTTTTAATTGCATTTCTTATGCAG-3'); and Ross et al. [12]-Gp-9.for (5'-

GGAGCTGATTATGATGAAGAGAAAAT-3'), Gp-9.rev (5'-AGCACAGCTTCAGCTGCTAAGA-3'), all_b.rev (5'-AGCACAGCTTCAGCTGCTAAGAT-3') and all_b.for (5'-GGAGCTGATTATGATGAAGAGAAAATA3 '). Eight microsatellite loci were analysed in 30 ants using the Multiplex system with primers described by Krieger and Keller [19]. Fluorescence labeling was manufactured by Applied Biosystems TM. Samples were genotyped by capillary electrophoresis in an ABI 3130 automatic sequencer (Applied Biosystems TM) and analyzed using the Genemapper ${ }^{\circledR}$ application (Applied Biosystems TM). The alleles of the most polymorphic locus were cloned into competent bacteria and subsequently sequenced for sequence confirmation and stutter occurrence verification.

\section{Results and Discussion}

Sequencing showed that the mtDNA of ten analyzed worker ants showed $99 \%$ similarity with S. invicta haplotype 41 deposited in GenBank (access number AY950736.1). Amplification with primers for social condition showed that the colony is monogyne and that the number of microsatellite alleles varied from one to seven for the eight loci (Table 1).

Alleles in the most polymorphic locus (Sol 55) were sequenced and compared with the sequence deposited in GenBank (AF002236.1) (Figure 1). The genotyping error was plus or minus one base pair. The sequences and respective alleles, together with the GenBank accession number, are as follows: sequence 146-genotyped as allele 147 (KP734174); sequence 150-genotyped as allele 149 (KP734172); sequence 152-genotyped as allele 153 (KP734171); sequence 154-genotyped as allele 155 (KP734173), sequence 158-genotyped as allele 157 (KP734169); sequence 160-genotyped as allele 161 (KP734168); and sequence 164-genotyped as allele $\mathbf{1 6 3}$ (KP734170). An additional allele was recorded during genotyping; this allele has the same primer sequences but 
Table 1. Allele number and frequency of the eight microsatellite loci identified in a Solenopsis invicta nest in São Paulo. The alleles used in sequencing characterization are highlighted.

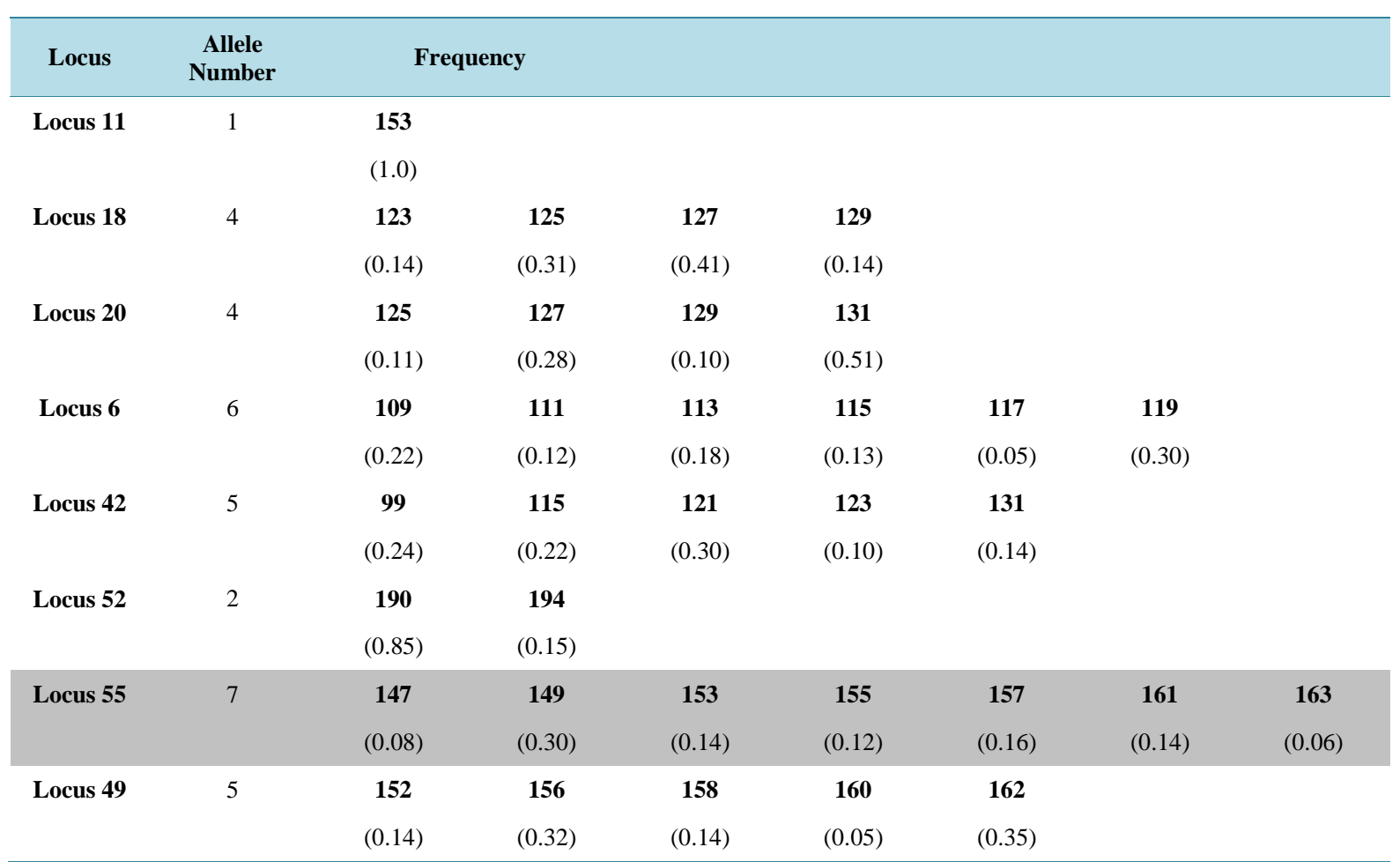

\begin{tabular}{|c|c|c|c|c|c|c|c|}
\hline & $\cdot|\ldots|$ & 15 & 25 & 35 & 45 & 55 & 65 \\
\hline 60 & СTCGCTTTCT & CAGTAAGCCG & GCGCGAGAAC & GGGCGTCGCT & GCGCCGCCGG & GACGCCAAGG & TCACCGGA. \\
\hline 158 & CTCGCTTTCT & CAGTAAGCCG & GCGCGAGAAC & GGGCGTCGCT & GCGCCGTTGG & GAAGACAAGG & TCACCGGA \\
\hline 164 & СTCGCTTTCT & CAGTAAGCCG & GCGCGAGAAC & GGGCGTCGCT & GCGCCGCCGG & GACGCCAAGG & TCACCGGA \\
\hline 152 & CTCGCTTTCT & CAGTAAGCCG & GCGCGAGAAC & GGGCGTCGCT & GCGCCGCCGG & GACGCCAAGG & TCACTGGA \\
\hline 150 & CTCGCTTTCT & CAGTAAGCCG & GCGCGAGAAC & GGGCGTCGCT & GCGCCGCCGG & GACGCCAAGG & TCACCGGA \\
\hline 154 & CTCGCTTTCT & CAGTAAGCCG & GCGCGAGAAC & GGGCGTCGCT & GCGCCGCCGG & GACGCCAAGG & TCACCGGA \\
\hline 146 & CTCGCTTTCT & CAGTAAGCCG & GCGCGAGAAC & GGGCGTCGCT & GCGCCGCCGG & GACGCCAAGG & TCACCGGA. \\
\hline 166 & CTCGCTTTCT & CAGTAAGCCG & GCGCGAGAAC & GGGCGTCGCT & GCGCCACCGG & GACGCCAAGG & TCACCGGA \\
\hline 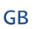 & CTCGCTTTCT & CAGTAAGCCG & GCGCGAGAAC & GGGCATCGCT & GCGC-GCCGG & GACGCCAAGG & TCACCGGA \\
\hline
\end{tabular}

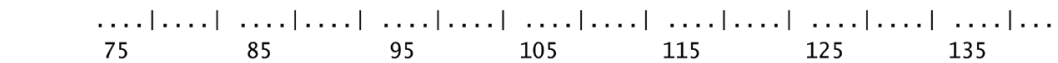

$$
\begin{aligned}
& 160 \text { CGGTCGGGCG CGCGAGC-AC GCCAGTTTTC TCTCTCTCTC TCTCTCTCTC TCTCTCT--- }--- \text { TCCTC } \\
& 158 \text { CGGTCGGGCG CGCGAGC-AC GCCTTITITC TCTCTCTCTC TCTCTCTCTC TCTCT---- - -- } \\
& 164 \text { CGGTCGGGCG CGCGAGC-AC GCCAGTTTTC TCTCTCTCTC TСTCTCTCTC TCTCTCTCTC T--ТCСTC } \\
& 152 \text { CGGTCGGGCG CGCGAGC-AC GCCAGTITTC TCTCTCTCTC TСTCTCTCT- } \\
& 150 \text { CGGTCGGGCG CGCGAGC-AC GCCAGTTTTC TCTCTCTCTC TCTCTCT-- } \\
& 154 \text { CGGTCGGGCG CGCGAGC-AC GCCAGTTTTC TCTCTCTCTC TСTCTCTCTC T-------- ---TCCTC } \\
& 146 \text { CGGTCGGGCG CGCGAGC-AC GCCAGTTTTC TCTCTCTCTC TCT-- } \\
& 166 \text { CGGTCGGGCG CGCGAGC-AC GCCAGTITTC TCTCTCTCTC TCTCTCTCTC TCTCTCTCTC TCTTCCTC } \\
& \text { GB } \\
& \text { CAGTCGCGGG CACGCACGAC GCCAGTTTTC TCTCTCTCTC ТСTCTCTCTC TCTCTCTCT- ---TCCTC }
\end{aligned}
$$

Figure 1. Sequences of the seven alleles identified in locus Sol55 in a Solenopsis invicta colony. The GB sequence refers to the GenBank sequence (AF002236.1) used to compare the identified alleles. Sequence 166 (red) corresponds to an unexpected allele.

a higher number of dinucleotide repeats (TC). This sequence, 166 (KP734175), is highlighted in red in Figure 1.

The number of alleles described in six of the eight loci analyzed was higher than expected for a haplodiploid crossing in a monogyne nest. The high number of alleles in the loci may be explained by a crossing between a queen ant with several males [20]. This situation has been observed only in introduced populations, and the first report was in South America, a region of natural occurrence. However, there are other possibilities: 1) the pri- 
mers used were not efficient in detecting social condition, see [8]; 2) the colony likely has more than one queen ant; or 3) the only mtDNA lineage found among the worker ants investigated may be evidence of a young nest founded by pleometrosis, with the queen ants still cooperating [21].

Allele 166 may have been considered a stutter, and therefore, it does not appear in genotyping. Alleles 164 and 166 differ by only two bases (C and T); it is possible that the source of allele 166 is associated with a replication error or other genetic mechanisms such as an insertion [22]. Consequently, the frequency determined was low, which hampered correct identification through fluorescence labeling.

\section{Conclusion}

The results of this study show that thorough colony analyses may reveal characteristics not explored in population analyses. The $S$. invicta populations reported in Brazil are considered to be evolutionarily and regionally independent and, possibly, many social behavior characteristics of native populations are unknown [23]. Increasing our knowledge of the diversity of the colony's social and genetic mechanisms may contribute to the development of control plans for this and other potentially invasive species. Moreover, these results may function as a warning or may alert researchers to the use of higher numbers of specimens in new studies of social insects to determine actual diversity.

\section{References}

[1] Bolton, B., Alpert, G., Ward, P.S. and Naskrecki, P. (2006) Bolton Catalogue of Ants of the World: 1758-2005. Harvard University Press, Cambridge.

[2] Antwiki (2015) http://www.antwiki.org/wiki/Welcome_to_AntWiki

[3] Lofgren, C.S., Banks, W.A. and Glancey, B.M. (1975) Biology and Control of Imported Fire Ants. Annual Reviews, 20, 1-30. http://dx.doi.org/10.1146/annurev.en.20.010175.000245

[4] Wojcik, D.P., Allen, C.R., Brenner, R.J., Forys, E.A., Jouvenaz, D.P. and Lutz, R.S. (2001) Red Imported Fire Ants: Impact of Biodiversity. American Entomologist, 47, 16-23. http://dx.doi.org/10.1093/ae/47.1.16

[5] Morrison, L.W., Porter, S.D., Daniels, E. and Korzukhin, M.D. (2004) Potential Global Range Expansion of the Invasive Fire Ant, Solenopsis invicta. Biological Invasions, 6, 183-191. http://dx.doi.org/10.1023/B:BINV.0000022135.96042.90

[6] Allen, C.R., Epperson, D.M. and Garmestani, A.S. (2004) Red Imported Fire Ant Impacts on Wildlife: A Decade of Research. The American Midland Naturalist Journal, 152, 88-103. http://dx.doi.org/10.1674/0003-0031(2004)152[0088:RIFAIO]2.0.CO;2

[7] Pitts, J.P., Mchugh, J.V. and Ross, K.G. (2005) Cladistic Analysis of the Fire Ants of the Solenopsis saevissima Species-Group (Hymenoptera: Formicidae). Zoologica Scripta, 34, 493-505. http://dx.doi.org/10.1111/j.1463-6409.2005.00203.x

[8] Shoemaker, D. and Ascunce, M.S. (2010) A New Method for Distinguishing Colony Social Forms of the Fire Ant, Solenopsis invicta. Journal of Insect Science, 10, 1-11. http://dx.doi.org/10.1673/031.010.7301

[9] Macom, T.E. and Porter, S.D. (1996) Comparison of Polygyne and Monogyne Red Imported Fire Ants (Hymenoptera: Formicidae) Population Densities. Annals of the Entomological Society of America, 89, 535-543. http://dx.doi.org/10.1093/aesa/89.4.535

[10] Tsutsui, N.D. and Suarez, A.V. (2003) The Colony Structure and Population Biology of Invasive Ants. Conservation Biology, 17, 48-58. http://dx.doi.org/10.1046/j.1523-1739.2003.02018.x

[11] Ross, K.G., Krieger, M.J.B., Shoemaker, D.D., Vargos, E.L. and Keller, L. (1997) Hierarchical Analysis of Genetic Structure in Native Fire Ant Populations: Results from Three Classes of Molecular Markers. Genetics, 147, 643-655.

[12] Ross, K.G, Krieger, M.J.B. and Shoemaker, D.D. (2003) Alternative Genetic Foundations for a Key Social Polymorphism in Fire Ants. Genetics, 165, 1853-1867.

[13] Ross, K.G., Gotzek, D., Ascunce, M.S. and Shoemaker, D.D. (2010) Species Delimitation: A Case Study in a Problematic Ant Taxon. Systematic Biology, 59, 162-184. http://dx.doi.org/10.1093/sysbio/syp089

[14] Ross, K.G. (2001) Molecular Ecology of Social Behaviour: Analyses of Breeding Systems and Genetic Structure. Molecular Ecology, 10, 265-284. http://dx.doi.org/10.1046/j.1365-294x.2001.01191.x

[15] Hebert, P.D.N., Cywinska, A., Ball, S.L. and de Waard, J.R. (2003) Biological Identifications through DNA Barcodes. Proceedings of the Royal Society of London Series B: Biological Sciences, 270, 313-321.

[16] Hebert, P.D.N., Ratnasingham, S. and de Waard, J.R. (2003) Barcoding Animal Life: Cytochrome $c$ Oxidase Subunit 1 
Divergences among Closely Related Species. Proceedings of the Royal Society of London Series B: Biological Sciences, 270, 596-599. http://dx.doi.org/10.1098/rsbl.2003.0025

[17] Ratnasingham, S. and Hebert, P.D.N. (2007) BOLD: The Barcode of Life System. Molecular Ecology Notes, 1-10. www.barcodinglife.org

[18] Valles, S.M. and Porter, S.D. (2003) Identification of Polygyne and Monogyne Fire Ant Colonies (Solenopsis invicta) by Multiplex PCR of Gp-9 Alleles. Insectes Sociaux, 50, 199-200. http://dx.doi.org/10.1007/s00040-003-0662-8

[19] Krieger, M.J.B. and Keller, L. (1997) Polymorphism at Dinucleotide Microsatellite Loci in Fire Ant Solenopsis invicta Populations. Molecular Ecology, 6, 997-999. http://dx.doi.org/10.1046/j.1365-294X.1997.00264.X

[20] Lawson, L.P., Vander Meer, R.K. and Shoemaker, D. (2012). Male Reproductive Fitness and Queen Polyandry Are Linked to Variation in the Supergene Gp-9 in the Fire Ant Solenopsis invicta. Proceedings of the Royal Society B: Biological Sciences, 279, 3217-3222. http://dx.doi.org/10.1098/rspb.2012.0315

[21] Manfredini, F., Riba-Grognuz, O., Wurm Y, Keller, L., Shoemaker, D. and Grozinger, C.M. (2013) Sociogenomics of Cooperation and Conflict during Colony Founding in the Fire Ant Solenopsis invicta. Plos Genetics, 9, 1-15. http://dx.doi.org/10.1371/journal.pgen.1003633

[22] Sia, E.A., Jinks-Robertson, S. and Petes, T.D. (1997) Genetic Control of Microsatellite Stability. Mutation Research, 383, 61-70. http://dx.doi.org/10.1016/S0921-8777(96)00046-8

[23] Ross, K.G., Krieger, M.J.B., Keller, L. and Shoemaker, D.D. (2007) Genetic Variation and Structure in Native Populations of the Fire Ant Solenopsis invicta: Evolutionary and Demographic Implications. Biological Journal of the Linnean Society, 92, 541-560. http://dx.doi.org/10.1111/j.1095-8312.2007.00853.x 